\title{
Currículo, necropolítica e política de afetos: 0 espaço-tempo do Projeto Africanidades
}

\section{Curriculum, necropolitics and politics of affections: the space-time of the Africanidades Project}

\section{Currículum, necropolítica y política de los afectos: el espacio-tiempo del proyecto Africanidades}

\author{
Luciane dos Santos Silva ${ }^{1}$
}

DOI: http://dx.doi.org/10.20435/serie-estudos.v26i58.1598

\begin{abstract}
Resumo: Este trabalho tem como objetivo analisar a produção curricular do Projeto Africanidades, motivado pela Lei 10.639/2003. O Currículo Mínimo do Estado do Rio de Janeiro tem representado elementos norteadores que produzem uma agência negra totalizada e homogênea. Tal propensão se articula em um movimento necropolítico, cuja tentativa é direcionada a fixar sentidos $a$ priori, tanto para negro quanto para currículo, fixando diferenças. Dificultando ações políticas antirracistas nas produções curriculares, no que tange à estrutura e agência, reforçando dicotomias, determinismos e significados postos. Diante desse panorama, com base em aportes teóricos pós-coloniais, argumento que todo currículo é híbrido e ambivalente, assim a Lei 10.639/2003 pode também performar currículos mais fluidos e enunciativos, em que a agência negra seja representada de forma descentrada e múltipla. Como a produção curricular do Projeto Africanidades, lócus enunciativo que se constitui como política de afetos, em que se negocia com temporalidades distintas através da arte, criando uma cesura temporal em que a agência negra se constitui como diferença.
\end{abstract}

Palavras-chave: currículo; agência negra; pós-colonial.

Abstract: This work aims to analyze the curricular production of the Africanidades Project, motivated by Law 10.639/2003. The Minimum Curriculum of the State of Rio de Janeiro has represented guiding elements that produce a totalized and homogeneous black agency. Such propensity is articulated in a necropolitical movement, whose attempt is directed to fix meanings a priori, both for blacks and for curriculum, fixing differences. Making anti-racist political actions difficult in curricular productions, with regard to structure and agency, reinforcing dichotomies, determinisms, and meanings. Given this panorama, based on postcolonial theoretical contributions, I argue that every curriculum is hybrid and ambivalent, so Law 10.639/2003 can also perform more fluid and enunciative curricula, in which black agency is represented in a decentered and multiple way. As the curricular production of the Africanidades Project, an enunciative locus that

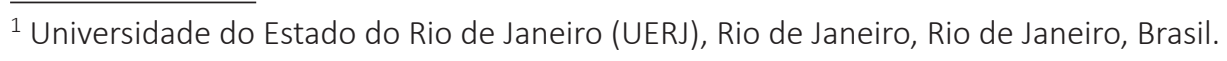


constitutes itself as a politics of affections, in which different temporalities are negotiated through art, creating a temporal caesura in which black agency is constituted as a difference..

Keywords: curriculum; black agency; postcolonial.

Resumen: Este trabajo tiene como objetivo analizar la producción curricular del Proyecto Africanidades, motivado por la Ley 10.639/2003. El Currículo Mínimo del Estado de Río de Janeiro ha representado elementos rectores que producen una agencia negra totalizada y homogénea. Tal propensión se articula en un movimiento necropolítico, cuyo intento se dirige a fijar significados a priori, tanto para los negros como para el currículo, fijando diferencias. Dificultar las acciones políticas antirracistas en las producciones curriculares, en cuanto a estructura y agencia, reforzando dicotomías, determinismos y significados. Ante este panorama, con base en aportes teóricos poscoloniales, sostengo que todo currículo es híbrido y ambivalente, por lo que la Ley 10.639/2003 también puede realizar currículos más fluidos y enunciativos, en los que la agencia negra está representada de forma descentrada y múltiple. Como producción curricular del Proyecto Africanidades, un locus enunciativo que se constituye como una política de afectos, en la que a través del arte se negocian diferentes temporalidades, creando una cesura temporal en la que la agencia negra se constituye como una diferencia.

Palabras clave: currículo; agencia negra; poscolonial.

\section{INTRODUÇÃO}

Em 2021, a Lei Federal 10.639/2003 (BRASIL, 2003), que estabelece a obrigatoriedade do ensino de história e cultura afro-brasileira nos currículos da educação básica, completa 18 anos de sancionada. Ancorada por essa força coletiva que a legislação proporciona, que este texto tem por referência a luta por uma educação antirracista, objetivando refletir sobre a luta política empreendida na produção curricular do Projeto Africanidades, como uma prática cultural e artística que envolve a negociação de posições ambivalentes de controle e resistência com as políticas educacionais.

A legislação problematiza a monoculturalidade nos currículos e torna evidente ações micropolíticas antirracistas nos contextos escolares, à medida que uma cultura e uma agência negra passaram a ser destacadas no texto curricular, entendido aqui de forma ampla: a oralidade, as legislações educacionais, livro didático e paradidático, datas comemorativas, rituais escolares.

A Secretaria de Estado de Educação do Rio de Janeiro (SEEDUC) solicitou que todas as escolas, em consonância com o Currículo Mínimo do Estado (CM), tornassem-se aplicáveis à Lei 10.639/2003, através do Projeto Africanidades. No entanto, ao institucionalizar a representação de culturas de forma diversa, são suturadas à identidade negra características inerentes. 
Produzindo uma ficção de fixidez de identidades, propensão que se articula em um movimento necropolítico, cuja tentativa é direcionada a incrustar sentidos a priori, tanto para negro quanto para currículo, fixando diferenças. Dificultando ações políticas antirracistas nas produções curriculares, no que tange à estrutura e agência, reforçando dicotomias, determinismos e significados postos.

Diante desse panorama, uma unidade escolar situada na cidade de Duque de Caxias, na região metropolitana $V$, inseriu a legislação referida ao Projeto Político Pedagógico da escola. Em 2021, a sua 14ạ Edição, "Parem de nos Matar", envolve atividades relacionadas a teatro, música, grafite, rodas de conversa (ponto fulcral do Projeto), Slam, um Grêmio chamado Dandara, fotografia, literatura, cinema, entrevistas, entre outros.

A produção curricular do Projeto é pautada em uma dinâmica que alia, ao mesmo tempo, elementos norteadores das políticas educacionais com as demandas contemporâneas dos alunos. Performando ações artísticas como políticas na busca por desestabilizar e desconstruir mecanismos que tentam fixar a diferença - uma necropolítica. Atuando em um espaço-tempo em que sentidos socialmente construídos, são negociados, e categorias como currículo e negro são elaboradas no seu presente enunciativo.

Este artigo é resultado de entrevistas individuais e grupos focais, diário de bordo e observação participativa. Organizo a apresentação do texto em três partes e as considerações finais, apresento a importância da Lei 10.639/2003 na concepção de currículo como texto político. Na segunda parte, explico os processos necropolíticos que permeiam a produção curricular tentando fixar diferenças e, na terceira parte, concentro-me na análise da produção curricular do Projeto Africanidades, como lócus enunciativo de afetos na luta antirracista.

Para fins de considerações finais, destaco que o Projeto Africanidades performa uma produção curricular constituindo-se como lócus enunciativo, potência de afetos, em que os sujeitos como produtores artísticos e agentes políticos são capazes de se construírem nessa liminaridade, um Terceiro - Espaço, agonístico (prescritivo e performático), em que a iteração que embasa os fragmentos constitutivos da luta antirracista na escola, na constituição da produção curricular, possa negociar elementos antagônicos e oposicionais sem uma superação dialética ou transcendente, in media res. 


\section{CURRÍCULO COMO TEXTO POLÍTICO}

Em contextos pós-coloniais, a linguagem da economia política não está encerrada no totalitarismo extremista do colonizador e nem na representação aquiescente do colonizado. Se entendida como espaço de significação, interpretação que permite interrogar significados postos, a historiografia demonstra, sob uma análise bem acurada, que o político é uma emergência in media res.

Assim, de acordo com Maar, a aquisição de significado político pode ser observada diariamente, "[...] quando trabalhadores conseguem transformar suas reivindicações em aumentos efetivos. Ou quando o governo usa um pelego para refrear estas mesmas reivindicações" (MAAR, 1994, p. 65), o autor descreve o caráter dinâmico e discursivo da política, dissociado da noção de ideias preconcebidas.

Apresenta o político como algo em construção, promovendo articulações que criam regimes de verdade, mas não princípios absolutos, são formações que precisam ser analisadas no contexto em que foram produzidas. Nesse sentido, toda e qualquer representação dicotômica política e a-política precisa ser repensada e retirada dos pressupostos estáticos que a definiram.

O que os exemplos referentes aos trabalhadores demonstram é que a linguagem da economia política é ambivalente e que só adquire a característica da politicidade à medida que os interesses sociais deixam de ser singulares e específicos, tornando-se objetos políticos, assumindo validade geral. Nesses termos, o momento de aquisição do significado político por um movimento social estaria relacionado à capacidade de hegemonizar interesses sociais específicos como objetivos políticos amplos.

Os movimentos sociais negros ao longo da historiografia brasileira fizeram essa articulação política in media res, nas perspectivas dos autores:

A articulação social da diferença, da perspectiva da minoria, é uma negociação complexa, em andamento, que procura conferir autoridade aos hibridismos culturais que emergem em momentos de transformação histórica. (BHABHA, 2014, p. 21).

Corrobora Hall (2009, p. 57):

O pós-colonial é estruturado na dominância, mas não pode controlar ou saturar tudo dentro da sua órbita. De fato, entre seus efeitos inesperados estão as formações subalternas e as tendências emergentes que escapam a seu controle, mas que ele tenta homogeneizar. 
Nesse sentido defendido por Bhabha, a autoridade pós-colonial não é absoluta na sua linguagem de dominação, ainda que sejam potentes e reiterados seus discursos, estes são ambivalentes. O que significa compreender que a resistência ou a diferença coexiste em uma mesma inscrição, sem relativizar a assimetria do poder. Contudo, ressaltando as paisagens híbridas dos contextos pós-coloniais, em uma relação menos verticalizada, em que seja possível vislumbrar a emergência das diferenças, das contranarrativas, como os movimentos negros.

Assim destaca Hall, ao defender a incapacidade do poder colonial em controlar todo o aparato do sistema colonialista, na tentativa de fixar as diferenças através de ações necropolíticas. Incapacidade expressa na insubmissão dos escravizados às regras do trabalho nas roças ou plantações onde trabalhavam, ao aproveitar as brechas do sistema para aprender a ler e a escrever e se organizando em resistências coletivas como os quilombos. Nesse decurso, as resistências precisaram engendrar, nos seus cotidianos, ações micropolíticas, em processos tradutórios de negociação agonística e iterativa.

Desses entremeios, o currículo como texto político recebeu novas leituras e interpretações com a Lei 10.639/2003, que solicita a inclusão, no currículo oficial da educação básica, da obrigatoriedade do ensino de história e cultura afro-brasileira. A legislação problematiza a monoculturalidade nos currículos e a ausência de representação do negro como resistência às estruturas dos processos colonizatórios.

Já que, de acordo com a pesquisadora Surya Aaronovich, "[...] ao longo da conformação do campo da educação, silenciou-se a questão racial. Via de regra, nas produções, a menção à população negra, quando acontecia, era feita na perspectiva da interdição" (BARROS, 2018, p. 04). Análise que abrange o campo do currículo no Brasil, em que os estudos começaram a se delinear no começo do século XX, diante da crença na educação como forma de alcançar o progresso.

Nessa chave de leitura, é possível a compreensão das experiências negras no Brasil, autorizadas em uma temporalidade da modernidade, em que a figura do negro foi construída inerte e ajustada à disposição colonial. Imbricada de restrições que pautaram as relações culturais, dispondo o negro e seus conjuntos de valores como inferior e o europeu como referência de conhecimento válido.

Dessa temporalidade, as teorias curriculares prescreveram seus conteúdos com base no conhecimento ditado pelo colonizador, ignorando que uma sociedade que passou por trezentos anos de escravidão não está incólume ao racismo. A 
centralidade desse conhecimento, concebido previamente às ações dos sujeitos, transforma o currículo em um texto pronto a ser ensinado e aprendido. A professora e pesquisadora Elizabeth Macedo (2012, p. 720) destaca que:

As tradições técnicas do campo do currículo enfatizaram as relações entre os programas educacionais e a vida social e econômica. Há, nessa tradição, um forte vínculo entre educação e controle social., o que definiria um projeto educacional para além do ensino.

Em um panorama recém-saído dos processos abolicionistas, início do século XX, Almeida e Sanchez (2016, p. 238) observam:

Nos registros das atividades das entidades negras aparecia o entusiasmo pela educação dos negros, vista como forma de superação de sua suposta inferioridade. Essa abordagem coincidiu com um período de entrada dos trabalhadores negros na indústria.

O currículo, nessa perspectiva teórica, como aponta Macedo, tinha por objetivo prover a formação de um mercado interno de mão de obra qualificada, por meio da instrução dos filhos de trabalhadores. O tecnicismo procurou gerir uma realidade sem contradições, negligenciando a escolarização da população negra, há apenas 41 anos da queda do veto que proibia a frequência dos escravos nas escolas públicas e 32 anos dos processos abolicionistas.

Neste período também, como distinguem Almeida e Sanchez, intelectuais negros demonstraram uma incipiente, mas intensa militância pelos direitos da população negra, em que a educação é pauta prioritária. Denunciavam a omissão do Estado em relação a políticas públicas de inserção e manutenção dos negros e ex-escravizados nas escolas públicas. E ofereciam alfabetização para crianças, jovens e adultos, defendendo a bandeira de que a educação poderia ser uma oportunidade de melhoria de vida e conhecimento para práticas políticas (SILVA; ARAÚJO, 2005).

Dessa forma, a história da educação e a do campo do currículo vão se performando em uma narrativa cindida e dupla, em um exercício de significação, a partir de uma cesura temporal. Urdida por uma temporalidade "[...] que atribui ao discurso uma autoridade que se baseia no preestabelecido" (BHABHA, 2014, p. 237), dificultando a escolarização dos negros. E por outra temporalidade "[...] processo de significação demonstrando os princípios do povo como contemporaneidade" (BHABHA, 2014, p. 237), a luta da população negra pela educação. 
Os projetos educacionais dos modelos técnicos foram colocados em xeque por deixarem de lado questões importantes, não só raciais, mas das desigualdades em geral na sociedade brasileira, ganhando relevância no Brasil desde o fim da ditadura militar, nos anos 1980, as teorias críticas de natureza marxista. "Tais textualidades questionam o modo como as relações de poder no interior da sociedade influenciam as decisões curriculares e são por elas influenciadas" (MACEDO, 2012, p. 722).

Nesses entretempos, recebe relevo, em 1930, as primeiras organizações negras com reivindicações políticas mais deliberadas (DOMINGUES, 2007). Destaca-se a Frente Negra Brasileira, "[...] essa entidade tinha por objetivo promover uma educação política, compreendendo-a como formação cultural e moral, e englobando também a instrução, ou seja, a alfabetização ou escolarização, com vistas a superar o atraso socioeconômico do negro" (ALMEIDA; SANCHEZ, 2016, p. 239).

Destaca-se, nesse período, o coletivo Teatro Experimental do Negro, criado no Rio de Janeiro em 1944, pelo militante e intelectual Abdias do Nascimento. Propondo uma legislação antidiscriminatória para o país, denunciou instituições escolares que não aceitavam alunos negros, inaugurou as denúncias aos preconceitos raciais em livros infantis e didáticos, e enfatizou a crítica ao currículo de orientação eurocêntrica (ALMEIDA; SANCHEZ, 2016).

Mesmo diante das demandas dos movimentos negros, a teorização crítica sobre o currículo se concentrou na análise da dinâmica de classe, porém logo percebeu que as relações de desigualdade e de poder na educação e no currículo não podiam ficar restritas à classe social. "Concentrando-se posteriormente em questões de acesso à educação e ao currículo, direcionando suas análises aos mecanismos sociais e institucionais, deixando de questionar o tipo de conhecimento que estava no centro do currículo" (SILVA, 2019, p. 99).

Macedo faz um movimento de aproximação entre as teorias aqui citadas, explicitando que, tanto nas técnicas quanto nas críticas, o papel da escola é a transmissão ou recriação do conhecimento, como aquisição para um projeto social mais amplo. "A escola é o lugar em que conhecimentos sociais, uma vez selecionados, são distribuídos, ensinados e aprendidos" (MACEDO, 2012, p. 724). Nesse sentido, o currículo como texto político mudou de foco na reprodução do status quo para uma resistência a ele, depois passou a abordar a resistência e a reprodução como uma relação dialética. 
Com a redemocratização do país, que se prolongou pelos anos 1980, ampliou a visibilidade dos movimentos sociais e, com isso, de demandas identitárias. Os Movimentos Negros que mantinham nesse momento um discurso mais universalista, "[...] à medida que foram constatando que as políticas públicas de educação, de caráter universal, ao serem implementadas, não atendiam à grande massa da população negra, o seu discurso e suas reivindicações começaram a mudar" (GOMES, 2017, p. 33).

Assim no caso das políticas educacionais:

A demanda por acesso foi a bandeira da década, aos poucos substituída pela luta pela permanência na escola. A tensão entre o foco na igualdade de acesso e permanência mais as demandas por reconhecimento da pluralidade cultural do país se torna cada vez mais forte ao longo dos anos subsequentes. (MACEDO, 2014, p. 84).

Dessa forma, a temática da diferença emerge no campo do currículo, no Brasil, na década de 1990, com a entrada das tradições pós-coloniais e pós-críticas. Desloca-se ligeiramente o foco do conhecimento para a cultura, "[...] quando o currículo passou a ser problematizado como sendo racialmente enviesado" (SILVA, 2019, p. 99). Nesses estudos, o conhecimento é compreendido como prática de significação e, como tal, é a confluência de diversos discursos que, unificados, compõem uma perspectiva da realidade.

Embora alguns autores reclamem uma especificidade do conhecimento na produção curricular e um sentido mais uníssono dos conteúdos retirados como parte de um conjunto de valores válidos, são reivindicações que facultam discursos do conhecimento como culturas distintas e vão constituindo equivalências: diversidade, pluralidade, entre outros. Nesse panorama que a Lei 10.639/2003 é instituída como demanda antiga dos movimentos negros, deslocando o político no texto curricular.

A legislação problematiza um conhecimento que se pretende hegemônico, ampliando as possibilidades de entendimento entre estrutura e agência, pondo em relevo o racismo no campo do currículo a partir de uma leitura estrutural e relacional, evidenciando ações micropolíticas antirracistas nos contextos escolares, à medida que uma agência negra passou a ser destacada no texto curricular, entendido aqui de forma ampla - "o livro didático e paradidático, as lições orais, as orientações curriculares oficiais, os rituais escolares, as datas festivas e comemorativas" (SILVA, 2019, p. 101). 
Entretanto, torna-se importante repensar como essa agência negra tem sido representada nas produções curriculares. O Currículo Mínimo do Estado do Rio de Janeiro traz, no corpo do seu texto, elementos norteadores na defesa da diversidade e pluralidade de culturas, suturando características inerentes a uma dada agência negra, em um movimento necropolítco de fixar e inibir as diferenças, restringindo ações políticas antirracistas no currículo ao reforçar dicotomias, determinismos e significados postos; assim, compreender as estratégias que tentam fixar a diferença é imprescindível para a quebra de representação que advém dessas fixações.

\section{NECROPOLÍTICA}

A necropolítica, como discorre Mbembe (2019), é a possibilidade de desenvolver uma leitura política, da soberania e do sujeito, diferente daquela que herdamos do discurso filosófico da modernidade, em que a razão é tida como verdade do sujeito. Propõe o autor que se olhe para outras categorias fundantes menos abstratas e mais palpáveis, como a vida e a morte. Sem prescindir da racionalidade iluminista, sua argumentação relaciona a noção de biopoder de Foucault a dois outros conceitos, o estado de exceção e o estado de sítio.

Examino essas trajetórias pelas quais o estado de exceção e a relação de inimizade tornaram-se a base normativa do direito de matar. Em tais instâncias, o poder continuamente se refere e apela a exceção, à emergência e a uma noção ficcional do inimigo. (MBEMBE, 2019, p. 17).

Nesse diálogo primeiro com Foucault e posterior nos entremeios da construção do conceito com outros autores, como Fanon e Arendt, que o filósofo concede os deslocamentos no termo necropolítica. Sua interlocução se dá primordialmente com o curso "Em Defesa da Sociedade2", em que Foucault centraliza a questão racial intermediada com a guerra, "[...] abrindo um campo de reflexões que vai tornar cada vez mais visível e dizível que as guerras a partir dos séculos XVIII e XIX são, antes de tudo, movidas pelas raças e sua ficção calcada num racismo biológico-social" (LIMA, 2018, p. 25).

Se o biopoder é aquele domínio da vida sobre o qual o poder estabeleceu o controle, e para Foucault o maior exemplo disso é o Estado nazista, para Mbembe,

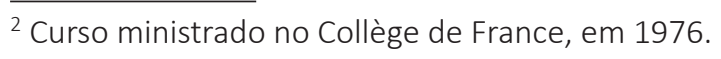


este controle não se ampara somente em deliberar quem vive ou quem morre, distingue-se notadamente nos contextos coloniais como a extinção da vida ou de colocá-la à iminência da morte. O poder de matar se configura na "exceção" e no apelo ao inimigo, que são reiterados constantemente pela prática política.

As práticas políticas no presente não podem mais ser encaradas simplesmente como uma ruptura ou "[...] um vínculo com o passado e o futuro, não mais uma presença sincrônica: nossa autopresença mais imediata, nossa imagem pública, vem a ser revelada por suas descontinuidades, suas desigualdades, suas minorias" (BHABHA, 2014, p. 24).

Assim, corrobora Konder (2000, p. 14), o próprio acervo de conhecimentos laboriosamente "[...] acumulados pelos seres humanos, ao longo dos séculos, precisa ser constantemente reexaminado: não podemos deixar de nos apoiar nele, é claro, mas devemos olhá-lo com desconfiança e questioná-lo implacavelmente".

Tanto Bhabha quanto Konder expõem possibilidades da importância da noção de necropolítica para análise de relações sociorraciais contemporâneas. Pensar a estratégia de uma política de morte a partir do processo colonizatório traz entendimento do que a escravidão e a ideia de negro, que se constituiu nesse período, ainda impactam em desigualdades educacionais, sociais e econômicas atuais. Traz a esperança que dessas frestas operou alguma forma de agência que hoje mobiliza e influencia forças para continuar desconfiando e questionando o colonialismo.

Na perspectiva pós-colonial aberta por Bhabha, a necropolítica como categoria de análise expande possibilidades referentes à modernidade, mais que com a ideia de sequencialidade e polaridade. Ao voltar o olhar para a escravidão, além de fragmentar narrativas, residi a análise de que "[...] os limites epistemológicos daquelas ideias etnocêntricas são também as fronteiras enunciativas de uma gama de outras vozes e histórias dissonantes, até dissidentes" (BHABHA, 2014, p. 24).

Mulheres, colonizados, negros, pessoas com sexualidades policiadas, entre outros, inseridos e articulados num movimento ambivalente nas histórias das migrações forçadas dos contextos coloniais e pós-coloniais. No mesmo contexto, as colônias são semelhantes às fronteiras. De acordo com Mbembe (2019, p. 35), para o colonizador:

As colônias não são organizadas de forma estatal e não criaram um mundo humano. Seus exércitos não formam uma entidade distinta, e suas guerras 
não são guerras entre exércitos regulares. Não implicam a mobilização de sujeitos soberanos (cidadãos) que se respeitam mutuamente, mesmo que inimigos. Não estabelecem distinção entre combatentes e não combatentes ou, novamente, "inimigo" e "criminoso".

A questão territorial é de suma importância para o necropoder, porque é nesse espaço que a soberania opera de diversas formas. Nas colônias, não existe uma lei equânime, a suspensão da lei é a normativa, em detrimento de relações microcapilares de poder. "A 'paz' tende a assumir o rosto de uma 'guerra sem fim" (MBEMBE, 2019, p. 32). As colônias tornam-se terras de ninguém, onde o caos e a desordem exigem "civilidade".

É nesse sentido que a fronteira também se torna o lugar a partir do qual algo começa a se fazer presente, destoa e mergulha no passado emoldurado embaixo de uma máscara que sugere harmonia e linearidade (KONDER, 2000). O necropoder tira essa máscara não para inserir outra, mas para compreender que universalizações a articularam, como a noção de raça, por exemplo, que se constitui em vetor de escolha de quem deve morrer e de quem deve viver, ou ainda de quem deve ser relegado à morte.

Nesse sentido, o Brasil nasceu de uma necropolítica:

Ou seja, nós nos constituímos desde o princípio e no seu fim numa zona de exceção. A exceção nos marca e os seus efeitos modelam as práticas discursivas reatualizando os traços de colonialidade, colocando em suspensão o que realmente almejamos ou queremos dizer quando falamos em democracia. (LIMA, 2018, p. 27).

O extermínio das populações indígenas, o sequestro, os tumbeiros e a escravização dos povos de Áfricas, todo o sistema colonizatório e sua pedagogia colonial consistem em insidiosos movimentos de necropoder. Discursos que atualizam e reatualizam estados de exceção e políticas de inimizade, o inimigo será criado não apenas nas políticas estatais de segurança pública, mas pelos meios de comunicação de massa e os programas de televisão (ALMEIDA, 2019).

Isso demonstra discursos embasados no mito da democracia racial, nas teorias de embranquecimento e do racismo à brasileira. O que configura em contextos brasileiros a necropolítica nos sistemas carcerários, nas populações em situação de rua, nos apartheids urbanos, no genocídio da população negra, que em sua maioria é jovem e masculina, na violência obstétrica em relação a 
mulheres negras e na vida das mulheres negras em geral, que mais morrem por diversos motivos nesse país.

Tais análises tornam-se pertinentes porque ainda há elementos fortes de colonialismo no Brasil, o que amplia a necropolítica como análise para pensar a morte por vias simbólicas. A imposição da língua dos colonizadores, dos conceitos de ciência e conhecimento europeus universalizados, de uma nova história - que, grosso modo, assemelha-se ao que experimentamos hoje como globalização (LOPES; MACEDO, 2011). O colonialismo opera, simbolicamente, ainda conforme as autoras, pela fixação de sentidos preferenciais, eliminando a possibilidade de pensar e dizer diferente.

É o que se busca fazer quando se substituem as línguas nativas pela do colonizador, é o que está em jogo quando a ciência iluminista é apresentada como aquela que tem as respostas para controlar os fenômenos naturais. Também isso que se quer conseguir quando se nomeiam os sujeitos como "outros", criando estereótipos. São formas de colonialismo que estão presentes nas nossas práticas cotidianas.

No campo do currículo a noção de necropolítica pode ser pensada a partir da tentativa de fixação de sentidos, por inibir a produção da diferença delineando um currículo a priori, precipitando identidades, direcionando sujeitos, criando efeitos de poder - que da perspectiva da necropolítica é difuso e se situa no nível da vida. No entanto, o necropoder não pode estar dissociado da ambivalência e do hibridismo. Contudo, como salienta Macedo (2006, p. 106):

Embora a diferença seja a marca do sistema simbólico a que denominamos cultura - e as classificações binárias sejam parte fundamental desse sistema - elementos que podem perturbar os sistemas classificatórios, ocupando regiões ambivalentes, ambíguas, são frequentemente banidos ou pressionados para se manter dentro das fronteiras simbólicas estabelecidas pelas culturas.

E Bhabha (2014, p. 193):

Não podem ser desprezadas as tentativas do poder colonial de aniquilação das culturas subalternas, com seus procedimentos para marcar as diferenças, fechando classes de coisas e expelindo os elementos não classificáveis. Uma das principais estratégias discursivas do poder colonial para fixar sentidos e inviabilizar a diferença - o estereótipo.

Como a pesquisadora expõe, a diferença faz parte da cultura, mas tem sido interpretada na educação e no campo do currículo de forma relacional, 
direcionando à diversidade. Sua compreensão perpassa pela noção de diferença "entre", estabelecendo uma estética celebratória de culturas, na qual a comparação marca uma identidade aprioristicamente. Como nenhuma comparação está isenta de classificação e hierarquização, o negro só é negro se não for branco, definição que carrega uma dimensão politicamente construída sobre negritude.

No caso do Brasil, que decorre 133 anos dos processos abolicionistas, ser negro está enclausurado em significantes, marcadores corporais, como cor da pele, traços físicos que homogeneizaram o negro naturalizando uma identidade. Constitui-se uma diferença entre preexistentes e impede significações além das já existentes. Nessa relação, o branco identidade modelo, padrão, superior, cria o negro sob uma identidade subalterna, inferior, degradante.

Essa relação binária é reforçada e atualizada pelo estereótipo, que, na defesa de Bhabha, é completamente ambivalente, o negro é ao mesmo tempo selvagem (canibal) e ainda o mais obediente e digno dos servos (o que serve a comida); ele é a encarnação da sexualidade desenfreada e, todavia, inocente como uma criança; ele é místico, primitivo, simplório e, todavia, o mais escolado e acabado dos mentirosos e manipulador de forças sociais.

Oscilações de representação que, ao vacilar nas tentativas de fixação e obsessivamente serem reiteradas, indicam a impossibilidade de nomeação definitiva e o escape de sentidos que se busca encapsular. Ambiguidades que revelam a necessidade de construção de saberes sobre o corpo negro, pois o que sabe do negro é arma para dominá-lo. Saber vacilante, exaustivamente repetido para simular uma verdade aceitável.

A necropolítica, na sua força simbólica, age nas produções curriculares quando trabalha a cultura "[...] como objeto epistemológico presa dentro do círculo hermenêutico, na descrição de elementos culturais em sua tendência a uma totalidade" (BHABHA, 2014, p. 285), atrelando à agência negra uma representação ligada a negro=corpo=instinto em detrimento do branco=mente=razão, concepção de racionalidade iluminista.

Movimento que fixa o significante negro em um conjunto de valores cujo reflexo induz a equivalências, tais como essência corpórea - músculos, emoções e instintos - e uma ludicidade - ritmos, cores e sabores. Tais equivalências são reiteradas nas produções curriculares normalmente no mês de novembro, mês da 
consciência negra, quando os signos da escravidão são interpretados posicionando identidades e histórias não equivalentes às dos europeus.

Reencena-se a importância dos escravizados na alimentação, na religiosidade, nas danças, relacionando ao que Senghor, em 1939, destaca: "[...] a emoção é negra e a razão é helênica", movimentos que conduzem os sistemas de significação a uma subjetividade cultural negra única, formadora de uma identidade negra a priori, totalizada, oclusiva e fixa, tanto para alunos quanto para currículos.

Um currículo prescritivo que prevê adição de conteúdos ou a substituição de conteúdos faz emergir propostas curriculares que contemplem as culturas concebidas como repertórios de significados, fixos e homogêneos. Desses repertórios, acaba-se, então, por selecionar um conjunto de práticas culturais a serem trabalhadas pela escola. O que, por conseguinte, reflete em um trabalho com um conhecimento pré-dado, selecionado de um repertório para constituir um conjunto de conteúdos a ser ensinado/aprendido.

Conforma-se a educação a uma cultura preestabelecida, em que relações assimétricas de poder reproduzem com espelhamento os preconceitos e as desigualdades a que as culturas tidas como "subalternas" são alvo. Como o racismo, as discriminações e os diversos preconceitos que nomeiam o diferente. Das perspectivas pós-coloniais aqui defendidas, todo currículo é prática significatória, sendo assim, traz a marca da regulação colonial, mas também são híbridos e ambivalentes, logo outros sentidos sempre vão irromper.

Apesar do jogo necropolítico de fixar a diferença e estereotipá-la ser bem alicerçado e forte, "a diferença não é a outra cultura, mas a criação de novos sentidos no ambiente regulado pelos sistemas discursivos e hegemônicos" (LOPES; MACEDO, 2011, p. 214), o que concede a noção de cultura um caráter fluído e movediço, transposto para o campo do currículo, contrapõe o caráter estático de pluralidade e ressalta os processos híbridos pelos quais as culturas estão sempre a se compor nas produções curriculares.

Tal como a produção curricular do Projeto Africanidades que irrompe em meio ao racismo estrutural, as legislações e uma rede de sentidos necropolíticos. Na performance de um currículo resistência, diferença que se compõe e recompõe em um ato de negociação política e cultural. Criando uma liminaridade disjuntiva, um espaço-tempo em que os sujeitos emergem como produtores culturais e 
agentes políticos, imbricados por experiências estéticas que ampliam a potência dos afetos na luta antirracista.

\section{POLÍTICA DE AFETOS}

Para compreender o Projeto Africanidades como representação, é preciso imergir no seu lócus enunciativo, na sua potência de afetos. Para o filósofo europeu do século XVII, Baruch Spinoza (2009, p. 163), "[...] por afeto compreendo as afecções do corpo, pelas quais sua potência de agir é aumentada ou diminuída, estimulada ou refreada e, ao mesmo tempo, as ideias dessas afecções". Nessa leitura:

Afetar-se é, pois, coexistir, compartilhar, com outros, uma realidade comum. O afeto é energia, humores, emoções, inflexões, desejos, paixões, sensações que produzem as experiências tais como são vivenciadas. O afeto produz "presença", reunindo movimentos vários. (RIBEIRO, 2020, p. 87).

O Africanidades, na sua 14ạ edição, tem no formato que é atualmente ensejado e afetado por ações políticas antirracistas bem contundentes, facultando e desdobrando outras possibilidades de realidades no contexto escolar. Em 2015, o tema foi: Meninas de black, meu cabelo não quer a sua progressiva; em 2016, Aprendendo pelos movimentos - o foco foram os Movimentos Sociais Negros; e, em 2017, foi abordado o Hip-hop: musicalidade, oralidade, literatura e resistência negras.

Já em 2018, As pretas e os ismos da nossa história: escravismo, racismo e machismo - Carolina Maria de Jesus foi homenageada; em 2019, foi o Afrocinemusicalidade, neologismo criado pelo professor Hélio, de sociologia que foi tema da sua dissertação de mestrado; em 2020, a escolha foi por Vidas negras importam; e 2021, Parem de nos matar.

A temática é trabalhada ao longo do ano com culminância em setembro, produzindo presença, enunciação, no que se refere à estrutura e agência. Através da arte, o Projeto reúne fragmentos de sentidos em movimentos tradutórios e ressignifcativos. Acolhendo os diversos tipos de agências negras que chegam à escola, desconstruindo e desestabilizando as necropolíticas do racismo estrutural. A enunciação na linguística, de acordo com Fiorin (1996, p. 19), pressupõe que:

Foram as teorias do discurso que deram a maior contribuição para o entendimento da instabilidade, pois quando se pensa em enunciação apenas como apropriação individual do sistema, concebe-se a língua como algo preexistente ao ato enunciativo, como algo independente dele, como algo 
autônomo que nada deve a ele. No entanto, se é verdade que a enunciação se vale de formas estereotipadas e esquemas canônicos e de normas, também cria modos de dizer. É uma práxis, que, ao trabalhar a língua, não só a emprega mas também a constitui, num jogo de estabilidades e instabilidades.

O pós-colonial da perspectiva de Bhabha (2014) propõe pensar a cultura como prática de enunciação, desloca o sentido da cultura como objeto epistemológico e de conhecimento empírico, confabulado em sistemas de significação unívocos e fixos, para interrogá-la a partir de uma leitura ambivalente e híbrida. Essa propensão interroga a própria enunciação em sua inscrição, à medida que a descola do individual, do pré-dado e das totalizações de identidades coletivas únicas.

Se a cultura como símbolos e sentidos produzidos num processo ambivalente (LOPES; MACEDO, 2011), que envolve reiterar e negar, num movimento próprio da cultura, que possibilita algum controle dos sentidos, ao mesmo tempo inviabiliza que esse controle seja total; cultura como enunciação envolve formas estereotipadas, esquemas canônicos e de normas, mas também diferença. A prática enunciativa avança de um modo mais dialógico imbricada em afastamentos e realinhamentos, resultados de antagonismos e articulações culturais.

Produzindo um espaço-tempo em que o currículo do Projeto Africanidades, pela arte que é produtora de afetos, desloca os signos postos da modernidade que normatizam noções de negro e currículo, recriando-os no seu presente enunciativo. Segundo (DELEUZE; GUATTARI, 1992, p. 227) o artista, é quem “[...] apresenta, inventa e cria os afetos em relação às perspectivas que eles nos dão. Somos afetados e nos transformamos através da produção de suas obras".

O aluno Wanderson, do segundo ano do Ensino Médio, relata:

Eu tinha problema com a minha pele, com meu cabelo, com a minha religião, eu me odiava, não gostava de tirar foto, tinha receio de falar em público e aceitava várias piadas racistas por medo. Quando escolhi a música "negro drama" para ler no final do Projeto, durante o período que fui treinando, lendo no espelho, passei a ter orgulho de mim, de quem sou.

Compartilha Júlia, aluna do segundo ano do Ensino Médio: "O projeto me ajudou a entender muitas coisas sobre a minha mãe que tem a pele retinta. Fiquei muito assustada com uma frase pichada no banheiro "as pessoas negras têm que morrer".

Logo depois, a escola foi grafitada com imagens de personalidades negras, inclusive o banheiro. Destaca a aluna Ana Clara, do terceiro ano do Ensino Médio: 
"Conhecer o livro 'Quarto de Despejo', da escritora Carolina Maria de Jesus, me deu coragem para escrever e entender como é ser artista, a Carolina era uma artista. Na minha familia tem muitas mulheres artistas e não são entendidas".

A forma como o Projeto incita o envolvimento dos alunos a trabalharem com as artes de autoria negra inter-relaciona experiências, mas também produz singularidades, modos de desconstruir efeitos do racismo estrutural, quebrando uma representação de identidade negra reificada e ligada a uma "angústia de origem", elo pautado somente em vivências da escravidão e das restrições do colonialismo. A arte faculta novas leituras de mundo e alianças forjadas na resistência, trazendo para o presente enunciativo uma agência negra através de suas afetações.

O professor Cristiano, de História, expõe:

O projeto na escola é um processo. A escola já negou o racismo, já entendeu ofensas como brincadeiras, muitas vezes não deu suporte ao trabalho por acreditar que o racismo não acontecia ali, hoje a escola atua de maneira intensa, temos casos de racismo, mas conseguimos fazer a discussão.

Discussões que envolvem negociações com o Currículo Mínimo do Estado do Rio de Janeiro, em que as questões raciais não são abordadas em todos os anos de escolaridade e cujo foco é: "[...] o respeito à diversidade em suas manifestações" (RIO DE JANEIRO, 2012, p. 2). De acordo com a perspectiva pós-colonial dos estudos de (BHABHA, 2014, p. 69), "[...] a diversidade cultural é o reconhecimento de conteúdos e costumes culturais pré-dados".

O que significa que, apesar das boas intenções das propostas multiculturais e da diversidade de culturas, a diferença desse âmbito é reduzida a uma identidade homogênea, única e acabada. Definida numa estrutura pré-discursiva e posicionada num determinado espaço-tempo como objeto epistemológico.

E delineia um processo em que o negro e sua constituição histórica são conjunções paralelas a uma cultura mestra e hegemônica, caminhando sempre à margem, pelas bordas. Movimento que despreza o elemento negro como também fundante de uma nação brasileira, inserindo tudo que advém do continente africano como inferior, em virtude de uma cultura alçada como superior.

Nesse sentido, o Projeto Africanidades, conforme a filósofa Marilena Chauí, ao comentar o pensamento filosófico de Spinoza, aumenta a potência das pessoas de expandir seu território de ação, ampliando a sua independência, propiciando outras relações com os outros corpos (NOGUERA; ALVES, 2019). 
Na roda de conversa sobre colorismo, entendi porque a minha irmã foi quase expulsa do colégio, brigava quase todo dia, xingava muito, porque ela é mais preta que eu, e o cabelo dela é diferente também, mexiam muito com ela, muito mesmo". (Nath, segundo ano).

As diversas questões trazidas pelos alunos em relação à forma como o racismo estrutural os afeta problematizam a universalidade de uma identidade negra. O racismo como prática discursiva precisa ser compreendido não com generalidades, mas sua atuação em contextos específicos. Essa multiplicidade de maneiras de ser negro que pulula na escola é potencializada no Africanidades, estimulando os alunos a serem produtores culturais, artísticos.

Como destacam os autores: "[...] o artista é mostrador de afetos, inventor de afetos, criador de afetos, em relação com os perceptos ou as visões que nos dá. Não é somente em sua obra que ele os cria, ele os dá para nós e nos faz transformar-nos com ele, ele nos apanha no composto" (DELEUZE; GUATTARI, 1992, p. 227-8). A produção curricular torna-se uma correlação de afetações.

A cesura temporal criada na produção curricular do Africanidades demonstra que:

O poder da tradução pós-colonial da modernidade reside em sua estrutura performática, que não apenas reavalia os conteúdos de uma tradição cultural. Introduz um outro lócus de inscrição e intervenção, um outro lugar de enunciação híbrido, cisão temporal, ou entretempo da agência pós-colonial. (BHABHA, 2014, p. 334).

É desse entretempo que as posições discursivas dos sujeitos são fornecidas na produção curricular, uma temporalidade que não nega um pretérito, mas também não prefigura um futuro, desliza para um presente enunciativo. "Abrindo-se à produção de formas singulares de vida, onde os afetos começam a circular de outras formas e produzir outros efeitos" (SAFATLE, 2015, p. 9).

Uma relação que pressupõe que os processos de identificação são permanentemente inacabados, e que se manifestam na diferença e nas afetações com o outro, a alteridade. Esta projetada em um lócus de condições fronteiriças, em vez de lugar de transmissão de tradições nacionais, como o Africanidades, conjunção descontínua de atravessamentos políticos e culturais anômalos desse lócus.

Diante dessa exposição, é possível analisar que o Projeto Africanidades é diferença e produz afetações diferenciadas nos alunos, implodindo a noção de político no currículo como sentidos postos e totalizantes, construindo um currículo 
híbrido e ambivalente. Espaço-tempo que a agência negra se constitui no exercício da subjetividade da atuação política.

\section{CONSIDERAÇÕES FINAIS}

A Lei 10.639/2003 enseja novas formas de pensar o currículo como texto político, ao apresentar possibilidades de uma agência negra na produção curricular. Contudo, essa agência tem sido representada nas legislações, como o Currículo Mínimo do Estado do Rio de Janeiro, de forma totalizada e homogênea, construída a partir da noção de negro e suas culturas como objeto epistemológico. Impossibilitando ações políticas no currículo, no que tange à estrutura e agência, facultando sentidos postos, dicotômicos e deterministas.

Com a entrada das teorias pós-coloniais no campo do currículo, foi possível pensar a agência negra a partir de outra perspectiva, qual seja, das noções de ambivalência e hibridismo, possibilitando entender a agência como resistência à autoridade colonial como parte de todas as estruturas, em uma mesma inscrição, inclusive dos currículos. Não como um par binário gerando comparações e hierarquias, mas como singularidade, diferença em si.

Construída através de negociações em processos tradutórios e iterativos com uma temporalidade curricular voltada à tradição e à cultura como reificação e outra temporalidade direcionada aos movimentos enunciativos de fluxos e significação das culturas, perfazendo uma liminaridade, uma cesura temporal em que a diferença emerge num terceiro espaço, contingente e movediço.

Desse espaço-tempo disjuntivo que o Projeto Africanidades, a partir da Lei 10.639/2003, performa uma produção curricular negociando sentidos com a temporalidade do colonizador - o racismo estrutural, a necropolítca, os estereótipos, os sentidos postos - e a temporalidade dos colonizados - ações antirracistas, micropolíticas cotidianas, contranarrativas, sentidos contemporâneos.

Trabalhando com artes de autoria negra, politizando o texto curricular ao deslocar as noções de agência negra una e centrada para uma agência negra descentrada e coletiva, unida sob a identidade da diferença, da resistência. Transformando o currículo em uma política de afetos, cujas afetações desconstroem necropolíticas, abrindo o currículo para outras narrativas, existências e modos de ser negro. 


\section{REFERÊNCIAS}

ALMEIDA, Marcus; SANCHEZ, Livia. Os negros na legislação educacional e educação formal no Brasil. Revista Eletrônica de Educação, São Paulo, v. 10, n. 2, p. 234-46, 2016.

ALMEIDA, Silvio Luiz. Racismo estrutural. São Paulo: Pólen, 2019.

BARROS, Surya Aaronovitch. História da educação da população negra: entre silenciamento e resistência. Revista Pensar a Educação, São Paulo, v. 4, n. 1, p. 3-29, jan./mar. 2018.

BHABHA, Homi. O local da cultura. Belo Horizonte: UFMG, 2014.

BRASIL. Ministério da Educação. Lei n. 10.639/2003 (lei ordinária), de 9 de janeiro de 2003. Altera a Lei n. 9.394, de 20 de dezembro de 1996, que estabelece as diretrizes e bases da educação nacional, para incluir no currículo oficial da rede de ensino a obrigatoriedade da temática "história e cultura afro-brasileira" e dá outras providências. Diário Oficial [da] República Federativa do Brasil, Brasília, DF, 10 jan. 2003. Disponível em: http://www. planalto.gov.br/ccivil_03/leis/2003/l10.639.htm. Acesso em: 10 set. 2021.

DELEUZE, Gilles; GUATTARI, Felix. O que é a filosofia? Tradução de Bento Prado Jr. e Alberto Alonso. São Paulo: Editora 34, 1992.

DOMINGUES, Petrônio. Movimento negro brasileiro: alguns apontamentos históricos. Tempo [online], Niterói, v. 12, n. 23, p. 100-22. 2007.

FIORIN, José Luiz. As astúcias da enunciação. São Paulo: Ática, 1996.

GOMES, Nilma Lino. O movimento negro educador: saberes construídos nas lutas por emancipação. Petrópolis: Vozes, 2017.

HALL, Stuart. Da diáspora: identidades e mediações culturais. Belo Horizonte: Editora UFMG, 2009.

KONDER, Leandro. O Marxismo da melancolia. Rio de Janeiro: Editora Civilização Brasileira, 2000.

LIMA, Fátima. Bio-necropolítica: diálogos entre Michel Foucault e Achille Mbembe. Arquivos Brasileiros de Psicologia, Rio de Janeiro, v. 70, n. especial, p. 20-33, 2018.

LOPES, Alice Cassemiro; MACEDO, Elizabeth. Teorias de currículo. Rio de Janeiro: Cortez, 2011. 
MAAR, Wolfgang Leo. O que é política? São Paulo: Editora Brasiliense, 1994.

MACEDO, Elizabeth. Currículo, identidade e diferença. Rio de Janeiro: UERJ, 2014.

MACEDO, Elizabeth. Currículo e conhecimento: aproximações entre educação e ensino. Cadernos de Pesquisa, Rio de Janeiro, v. 42, n. 147, p. 716-37, 2012.

MACEDO, Elizabeth. Por uma política da diferença. Cadernos de Pesquisa, Rio de Janeiro, v. 36, n. 128, p. 327-56, maio/ago. 2006.

MBEMBE, Achille. Necropolítica. São Paulo: N-1 Edições, 2019.

NOGUERA, Renato; ALVES, Luciana. Infâncias diante do racismo: teses para um bom combate. Revista Educação e Realidade, Porto Alegre, v. 44, n. 2, [s.p.], 2019.

RIBEIRO, Adélia. A virada pós-colonial: experiências, trauma e sensibilidades. Revista Crítica de Ciências Sociais, Coimbra, n. 123, p. 77-96, dez. 2020.

RIO DE JANEIRO (cidade). Governo do Estado do Rio de Janeiro. Secretaria de Estado de Educação. Currículo mínimo - confira orientações. Rio de Janeiro: Secretaria de Estado de Educação, 2012. Disponível em: https://seeduconline.educa.rj.gov.br/curr\%C3\%ADculob\%C3\%A1sico. Acesso em: 22 maio 2021.

SAFATLE, Vladimir. Circuito dos afetos: corpos políticos. São Paulo: Cosac Naify, 2015.

SENGHOR, Leopold. Ce que I'homme noir apporte. Paris: Librairie Plon, 1939. (L'homme de Couleur).

SILVA, Geraldo; ARAÚJO, Marcia. Da interdição escolar às ações educacionais de sucesso: escolas dos movimentos negros. In: ROMÃO, Jeruse (Org.). História da educação dos negros e outras histórias. Brasília: Ministério da Educação, 2005.

SILVA, Tomaz Tadeu. Documentos de identidade. Belo Horizonte: Autêntica, 2019. SPINOZA, Benedictus. Ética. Tradução de Tomaz Tadeu da Silva. Belo Horizonte: Autêntica, 2009.

\section{Sobre os autores:}

Luciane dos Santos Silva: Doutoranda em Educação pela Universidade do Estado do Rio de Janeiro (UERJ). Mestra em Literatura Portuguesa e Africana pela UERJ. 
Graduada em Letras (Português-Literaturas) pela Universidade Federal do Rio de Janeiro (UFRJ/UBM). Professora na Educação Básica na Secretaria de Estado de Educação do Rio de Janeiro (SEEDUC/RJ). E-mail: lucianessga.75@gmail.com, Orcid: https://orcid.org/0000-0001-7607-1065

Recebido em: 10/09/2021

Aprovado em: 13/10/2021 